\title{
Targeted therapy of intracranial glioma model mice with curcumin nanoliposomes
}

This article was published in the following Dove Press journal:

International Journal of Nanomedicine

\author{
Ming Zhao* \\ Mengnan Zhao* \\ Chen Fu \\ Yang Yu \\ Ailing Fu
}

School of Pharmaceutical Sciences, Southwest University, Chongqing, People's Republic of China

*These authors contributed equally to this work
Correspondence: Ailing Fu

School of Pharmaceutical Sciences,

Southwest University, Tiansheng Road,

Beibei District, Chongqing 4007/6,

People's Republic of China

Tel/fax +86 236825 I 225

Emailfal@swu.edu.cn
Background: Glioma is the most aggressive and lethal brain tumor in humans, it comprises about 30 per cent of all brain tumors and central nervous system tumors.

Purpose: The objective of this study was to create novel brain-targeting nanoliposomes to encapsulate curcumin as a promising option for glioma therapy.

Patients and methods: Human glioma cells (U251MG) were used to determine cell uptake efficiency and possible internalization mechanism of the curcumin-loaded nanoliposomes modified by a brain-targeting peptide RDP. In addition, intracranial glioma mice model was prepared by transplantation of U251MG cells into the mice striatum, and then the liposomes were intravenously administered into the glioma-bearing mice to evaluate the anti-glioma activity.

Results: RDP-modified liposomes (RCL) could enter the brain and glioma region, and were internalized by the glioma cells perhaps through acetylcholine receptor-mediated endocytosis pathway. Furthermore, the RCL prolonged the survival time of the glioma-bearing mice from 23 to 33 days, and the inhibition mechanism of the RCL on glioma cell was partly due to cell cycle arrest at the $\mathrm{S}$ phase and induction of cell apoptosis.

Conclusion: This study would provide a potential approach for targeted delivery of drug-loaded liposomes for glioma treatment.

Keywords: glioma, targeted delivery, cell apoptosis, cell cycle, survival time

\section{Introduction}

Glioma is the most aggressive brain tumor with a high incidence and fatality rate. ${ }^{1,2}$ Although different therapeutic strategies have been explored to prevent the tumor growth, there is currently no effective drug treatment for this tumor. ${ }^{3-5}$ The main drawbacks of drug development for glioma treatment are that the candidate drugs lack the capacity to penetrate the blood-brain barrier (BBB) and tumor cell specificity. ${ }^{6-8}$

The $\mathrm{BBB}$ regulates the passage through which drugs are transported into the brain and prevents the drugs from penetrating the brain. ${ }^{9}$ To cross the barrier, brain-targeting delivery systems are developed to deliver therapeutic agents across the BBB, specifically into the brain. Among the targeting carriers, peptide derivatives of rabies virus glycoprotein (RVG) are suggested as potential delivery ligands to transport nanocarriers for treating various brain diseases, such as Alzheimer's disease, ischemic injury, protein misfolding diseases, and so on. ${ }^{10}$ We previously used an RVG peptide derivative, RDP, to deliver proteins and nanoparticles into the brain for disease treatment and cell imaging. ${ }^{11,12}$ The peptide shows high BBB-penetrating capability when it is conjugated to macromolecular cargoes. ${ }^{13}$

Nevertheless in glioma therapy, it is essential that the cargoes have cell selectivity between tumor and normal nerve cells. The lack of cell specificity of clinical chemotherapeutic drugs is another major issue that results in unsatisfied therapeutic effect and severe adverse reactions. However, some herbal medicinal constituents, such as curcumin, 


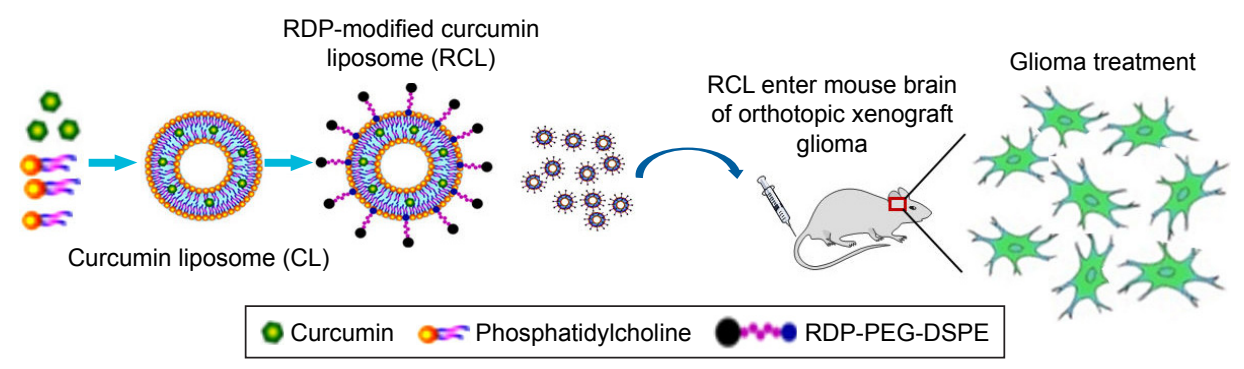

Figure I Schematic representation of the transport of RDP-modified curcumin nanoliposomes (RCL) into the brain for glioma therapy. The liposomes were prepared using thin-film hydration method. Then, the liposomes were intravenously injected into mice to determine their anti-glioma activity.

evodiamine, and catalpol, have distinct different effects on tumor and normal cells through different intracellular mechanisms, which do not affect normal cell viability while inhibiting tumor cell growth. ${ }^{14-16}$ Among these potential antitumor candidates, curcumin is a natural hydrophobic phenolic compound originally isolated from Curcuma longa $\mathrm{L}$. (turmeric) rhizomes. Increasing evidence has suggested that curcumin performs distinct activities to kill tumor cells through diverse mechanisms, leaving normal cells unaffected. ${ }^{17-19}$ For example, it is reported that curcumin shows antiproliferative activities in tumor cells via induction of cell apoptosis mediated by various signaling pathways, such as p53-dependent apoptosis pathway and deregulation of cyclin D1 expression. ${ }^{20,21}$ Moreover, curcumin has been shown to play neuroprotection roles in homocysteine rat model of Parkinson's disease and amyloid- $\beta$ induced mitochondrial dysfunction through scavenging oxygen species and preventing thiol group oxidation. ${ }^{22,23}$

Although the ability to kill tumor cells makes curcumin an attractive drug candidate, its application is strictly limited due to its poor water solubility and low bioavailability. In order to make curcumin feasible in glioma therapy in vivo, here we used RDP-modified nanoliposomes as curcumin brain-targeting delivery carriers to improve tissue targeting, water solubility, and biocompatibility (Figure 1). The results suggested that the curcumin-loaded RDP-liposomes (RCL) could effectively inhibit glioma cell growth and show an obvious therapeutic activity against intracranial glioma in the model mice.

\section{Materials and methods}

\section{Synthesis of RDP-PEG-DSPE}

RDP-PEG-DSPE was synthesized by linkage of terminal thiol group of RDP-cys (purity $>95 \%$; Shanghai Ji'er Biotech. Co., Shanghai, People's Republic of China) and NHS group of NHS-PEG-DSPE (PEG, 2000 of molecular weight; Nanocs Co., New York, NY, USA). ${ }^{24,25}$ Briefly, NHS-PEG-DSPE and RDP-cys were dissolved in $1 \mathrm{~mL} \mathrm{DMF}$ at a ratio of 2:1 (mol:mol), and then $20 \mu \mathrm{L} \mathrm{N}$-methyl morpholine was added to the mixture. Following $48 \mathrm{~h}$ of stirring, the mixture was dialyzed with a dialysis bag (MW 3500) to remove the free RDP. The product of RDP-PEG-DSPE conjugation was freeze-dried on a lyophilizer (Shanghai Binlon Instrument Co., Shanghai, People's Republic of China) and stored at $-20^{\circ} \mathrm{C}$ for use.

\section{Preparation of RCL}

The liposomes of different lipid compositions were prepared using thin-film hydration method. The gradients of $1 \mathrm{mg}$ curcumin (Sigma, St Louis, MO, USA), 2 mg cholesterol (Aladdin, Shanghai, People's Republic of China), $20 \mathrm{mg}$ soy lecithin (Aladdin), and $0.1 \mathrm{mg}$ RDP-PEG-DSPE were dissolved in $3 \mathrm{~mL}$ trichloromethane to form a yellow solution in the roundbottomed flask. Then, the solution was evaporated for $15 \mathrm{~min}$ using a Rotavapor which should be turned on the motor to turn the round-bottomed flask at $37^{\circ} \mathrm{C}$ for producing a dry film at $170 \mathrm{rpm}$. After the film was hydrated for $1 \mathrm{~h}$, the mixture was intermittently exposed to ultrasound for $90 \mathrm{~s}$ to obtain a pale yellow and transparent solution. The solution was filtered with a $220 \mathrm{~nm}$ filter to acquire uniform RDP-conjugated curcumin liposomes (RCL). Meanwhile, curcumin liposomes (CL) without $\mathrm{RDP}$ conjugation were prepared in parallel as a control.

An ultraviolet spectrometer (Shimadzu Corp, Kyoto, Japan) was used to observe the appearance of the liposomes under visible and ultraviolet light $(365 \mathrm{~nm})$. The liposome size, polymer dispersion index (PDI), and zeta-potential were respectively measured using Zetasizer Nano ZS (Malvern Instruments Ltd, Malvern, UK). The shape of the liposomes was respectively observed by transmission electron microscopy (TEM; H7500; Hitachi Ltd. Co., Tokyo, Japan) and atomic force microscopy (AFM; Bruker, Ettlingen, Germany).

\section{Entrapment efficiency}

Since curcumin exhibits autofluorescence at an excitation and emission wavelength of 440 and $475 \mathrm{~nm}$, respectively, its concentration was determined by fluorescence 
measurement. To detect entrapment efficiency of the RCL, the liposome solution ( $1 \mathrm{~mL}$ ) was centrifuged at $120,000 \mathrm{~g}$ for $1.5 \mathrm{~h}$, and then the supernatant was separated to quantify unentrapped curcumin using a fluorescence spectrophotometer (F-7000; Hitachi Ltd. Co.). Entrapment efficiency was calculated using the following formula: encapsulation efficiency $(\%)=\left[\left(C_{0}-C_{1}\right) / C_{0}\right] \times 100$, where $C_{0}$ refers to total curcumin in liposome preparation and $C_{1}$ to curcumin in supernatant.

\section{In vitro release}

In vitro release of curcumin from the liposomes was evaluated by dialysis method. Briefly, $1 \mathrm{~mL}$ liposomes (CL and RCL, respectively) was injected into a dialysis bag (MWCO 8,000 Da; Spectrum, Henderson, NV, USA), and then suspended in $30 \mathrm{~mL}$ release medium of PBS (Ph 7.4) and 2\% $\mathrm{SDS}$ at $37^{\circ} \mathrm{C}$ for shaking for $78 \mathrm{~h}$ at $100 \mathrm{rpm}$. Subsequently, $1 \mathrm{~mL}$ release medium was taken out for curcumin determination, and an equal amount of fresh release medium was added at several time points. The curcumin content in the release medium was detected using the fluorescence spectrophotometer, and half-time $\left(t_{1 / 2}\right)$ was calculated following first-order reaction kinetics.

\section{Cell culture}

Human glioma cells (U251MG) and HeLa cells were purchased from ATCC (Manassas, VA, USA), and were respectively cultured in Dulbecco's Modified Eagle's Medium (BioInd, Cromwell, CT, USA) (DMEM) supplemented with 10\% fetal bovine serum, 100 units $/ \mathrm{mL}$ penicillin, and $100 \mu \mathrm{g} / \mathrm{mL}$ streptomycin. The cells were incubated at $37^{\circ} \mathrm{C}$ under $5 \% \mathrm{CO}_{2}$ in a humidified incubator (Esco Micro Pte. Ltd., Singapore).

\section{Cell uptake}

The cells were cultured in 24-well plates for $24 \mathrm{~h}$ at $37^{\circ} \mathrm{C}$. When cell confluence reached $60 \%$, the media was replaced with fresh DMEM. Then, RCL were added into the media at a final concentration of $20 \mu \mathrm{M}$. After incubation for $6 \mathrm{~h}$, the cells were washed with PBS three times and observed under a confocal microscope (Zeiss, Oberkochen, Germany). The fluorescence intensity of curcumin in cells was measured by a fluorescence microplate reader (Tecan Infnite M200 PRO; Männedorf, Switzerland) using the wavelength of the maximum absorption peak at an excitation wavelength of $440 \mathrm{~nm}$ and an emission wavelength of $475 \mathrm{~nm}$.

\section{Mechanism of cellular uptake of RCL}

The U251MG cells were cultured in 96-well plates at a density of $1 \times 10^{4}$ cells/well for $24 \mathrm{~h}$. Then, the cells were respectively treated with endocytosis inhibitors or neurotransmitters, including $10 \mu \mathrm{M} \mathrm{NaN}_{3}, 40 \mu \mathrm{M}$ colchicine, $1 \mathrm{mM}$ amiloride, $1 \mu \mathrm{g} / \mathrm{mL}$ cytochalasin D (cyto-D), $20 \mu \mathrm{M}$ acetylcholine (Ach), and $\gamma$-aminobutyric acid (GABA). ${ }^{26}$ Following 30 min incubation, the media was replaced by fresh DMEM, and RCL were added at a final concentration of $20 \mu \mathrm{M}$. The cells were washed three times, and fluorescence intensity was detected using the fluorescence microplate reader.

\section{Cell viability measurement}

The cell viability of the U251MG cells was detected by MTT assay. Briefly, the cells were seeded in a 96-well plate at a density of $5 \times 10^{4}$ cells/well for $24 \mathrm{~h}$, and then they were respectively treated with the liposomes $(0,4,8,16,32$, and $64 \mu \mathrm{M})$ for $48 \mathrm{~h}$. Afterwards, the cells were washed with PBS three times, and then $20 \mu \mathrm{L}$ MTT $(5 \mathrm{mg} / \mathrm{mL})$ was added into each well for another $4 \mathrm{~h}$ incubation. After the media was removed, $150 \mu \mathrm{L}$ DMSO was added to measure the absorbance at $490 \mathrm{~nm}$ wavelength on a microplate reader (Bio-Rad, Hercules, CA, USA).

\section{Cell cycle and cell apoptosis detection}

The U251MG cells were plated in six-well plates. When cell confluence reached $80 \%$, the liposomes and free curcumin were respectively added into the media at a final concentration of $20 \mu \mathrm{M}$. After another $48 \mathrm{~h}$ incubation, the cells were collected with $0.25 \%$ trypsin/EDTA and centrifuged at $1,000 \mathrm{rpm}$ for $5 \mathrm{~min}$, and then fixed in $70 \%$ ethanol for $24 \mathrm{~h}$. Afterwards, cell cycle (propidium cell cycle assay kit; Beyotime Inst. Biotech., Shanghai, People's Republic of China) was measured using a flow cytometer (BD FACSVantage; San Jose, CA, USA). Moreover, after the cells were treated with RCL (final concentration, $20 \mu \mathrm{M}$ ), cell apoptosis (Annexin V-PE apoptosis detection kit; Beyotime Inst. Biotech.) was measured by flow cytometry.

\section{In vivo imaging}

Male BALB/c nude mice aged 4-5 weeks and weighing around $20 \mathrm{~g}$ (Permit Number: SCXK [Jing 2009-0015]) were purchased from Chongqing Medical University (Chongqing, People's Republic of China). Animals were used in the study according to the guidelines of the Institutional Animal Committee of Southwest University, Chongqing, and the animal experiments were approved by the Institutional Animal Committee.

RCL and CL were injected respectively into the tail veins of nude mice at the dose of $20 \mathrm{mg} / \mathrm{kg}$ of body weight. The mice were anesthetized using isoflurane following 
$2 \mathrm{~h}$ injection. After the mice were placed in the cassette of In-Vivo Imaging System FX Pro (Carestream, Rochester, NY, USA), X-ray and fluorescence images were captured, and then overlaid according to the protocol of the manufacturer (Carestream). Subsequently, the mice were euthanized by overdose with pentobarbital sodium $(50 \mathrm{mg} / \mathrm{kg})$, and the brain, heart, lungs, kidneys, and liver were dissected out for fluorescence imaging. The fluorescence images were taken at an excitation wavelength of $440 \mathrm{~nm}$ and an emission wavelength of $475 \mathrm{~nm}$.

\section{In vivo pharmacokinetics of the nanoliposomes}

The nanoliposomes were respectively injected into mice tail veins at the dose of $20 \mathrm{mg} / \mathrm{kg}$ of body weight, and then the mice were anesthetized by sodium pentobarbital $(30 \mathrm{mg} / \mathrm{kg})$. After injection for $0.5,1,3,6,12,24$, and $48 \mathrm{~h}$, plasma and brain were respectively separated ( $n=4$ for each time point). The fluorescence intensity of plasma and brain homogenate was measured by the fluorescence spectrophotometer.

Moreover, brain sections were prepared to further identify the location of curcumin in the brain. Two hours after injection of the nanoliposomes, the mice were euthanized and the brains were dissected out. The brains were fixed with $4 \%$ paraformaldehyde for $24 \mathrm{~h}$, and then dehydrated successively in $10 \%, 20 \%$, and $30 \%$ sucrose overnight at $4{ }^{\circ} \mathrm{C}$. Frozen coronal sections of the cerebrum of $30 \mu \mathrm{m}$ thickness were cut with a cryostat microtome (Leica CM1950; Wetzlar, Germany) and mounted on slides. The sections were observed with a confocal microscope.

\section{Preparation of intracranial glioma mice model and tissue imaging}

The mice were anesthetized through intraperitoneal injection of sodium pentobarbital $(30 \mathrm{mg} / \mathrm{kg})$, and then placed on a small animal stereotaxic apparatus. The U251MG cells $\left(1 \times 10^{6}\right.$ cells $\left./ 5 \mu \mathrm{L}\right)$ were microinjected into the right striatum of the mice at sites with the following stereotaxic coordinates: $+1.0 \mathrm{~mm}$ relative to bregma, $2.1 \mathrm{~mm}$ relative to midline, and $2.6 \mathrm{~mm}$ below the skull surface. The cells were injected slowly for $5 \mathrm{~min}$ at a rate of $0.5 \mu \mathrm{L} / \mathrm{s}$, and the syringe was placed for $5 \mathrm{~min}$ before withdrawing the needle. ${ }^{27}$ Then, the burr hole was sealed with bone wax. Two weeks later, the liposomes were respectively intravenously injected into the glioma-bearing mice at the dose of $20 \mathrm{mg} / \mathrm{kg}$ of body weight. Following $8 \mathrm{~h}$ injection, the mice were euthanized using pentobarbital sodium, and the tissues (brain, heart, lungs, kidneys, and liver) were removed for imaging.

\section{Therapeutic effect of the liposomes on glioma-bearing mice}

The glioma-bearing mice were randomly divided into four groups $(n=4-6)$. One group was used as model mice, and the other groups were respectively intravenously injected with RDP, RCL, and CL (20 mg/kg) once every 2 days three times at 7 days after cell transplantation. Then, the mice were euthanized by overdose of sodium pentobarbital, and the brains were respectively dissected out and fixed in $4 \%$ paraformaldehyde at $4{ }^{\circ} \mathrm{C}$, and then dehydrated in $10 \%, 20 \%$, and $30 \%$ sucrose. The brains were continuously sectioned, and the sections were stained with hematoxylin and eosin (HE). Tumor volume was calculated according to the formula $V=1 / 2 a b^{2}$, where a represents the longest diameter and $\mathrm{b}$ represents the shortest diameter. ${ }^{28}$ Moreover, survival time in the four groups ( $n=8-10$ for each group) was measured, and mean survival time was calculated to evaluate the therapeutic effect of the liposomes on the glioma-bearing mice.

\section{Statistical analysis}

All the data were expressed as mean $\pm \mathrm{SD}$. Student's $t$-test was used for comparisons between two groups, and ANOVA test was used for multiple-group analysis. The value $p<0.05$ was considered statistically significant.

\section{Results and discussion Characteristics of the nanoliposomes}

Since curcumin is insoluble in aqueous medium and has poor stability towards oxidation, light, and heat, it cannot be widely used in pharmaceutical industry. Here, we prepared a liposome formulation for curcumin application in vivo based on the excellent drug-loading performance of the liposomal carrier that not only improves the water solubility of poorly soluble drugs but also facilitates drug targeting and controlled release after modification. ${ }^{29,30}$

The aqueous solution of the prepared liposomes appeared yellow under visible light (Figure 2A-a) and exhibited green florescence under UV light (Figure 2A-b). When fluorescence of the liposome solution was excited at $440 \mathrm{~nm}$, its emission wavelength located at $475 \mathrm{~nm}$, which was consistent with that of free curcumin (Figure 2B). The size of RCL distributed at $45-130 \mathrm{~nm}$ with an average size of $\sim 98.6 \mathrm{~nm}$, and the PDI was $0.27 \pm 0.021$ as measured using dynamic light scattering (Figure 2C). In addition, the zeta-potential of RCL was $-3.94 \pm 0.47 \mathrm{mV}$, which was higher than that of CL $(-4.77 \pm 0.96 \mathrm{mV})$. Under TEM, RCL exhibited a smooth surface and a nanoparticle size (Figure 2D). Additionally, the liposomes were well dispersed without any aggregation 
A

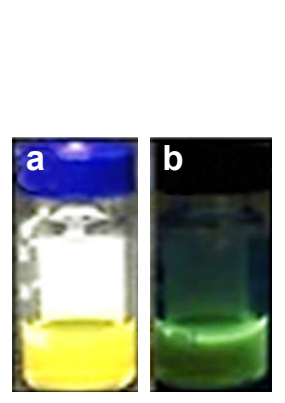

D

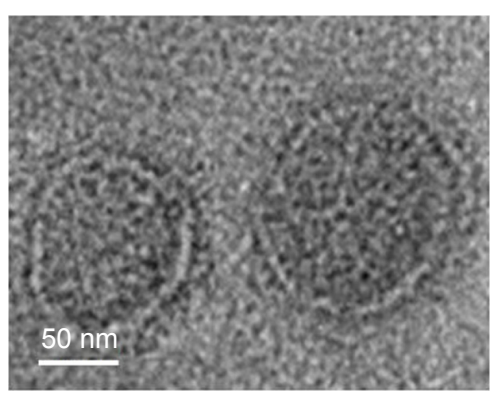

B

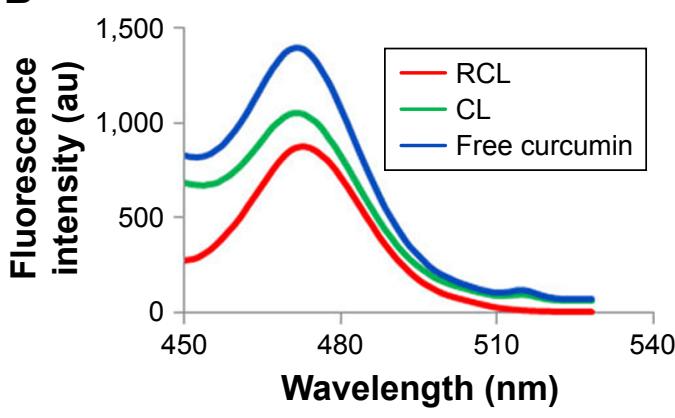

C

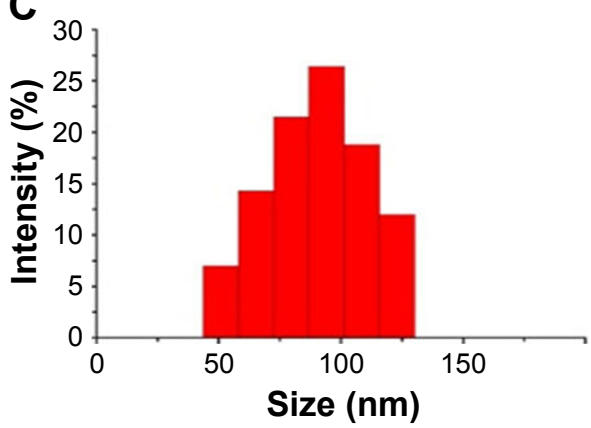

E

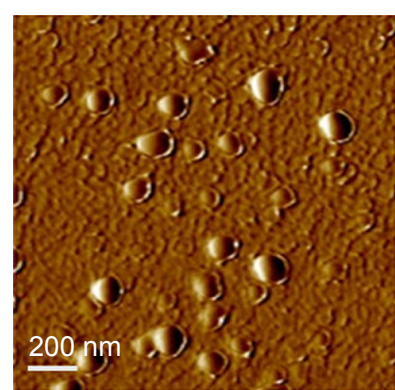

$\mathbf{F}$

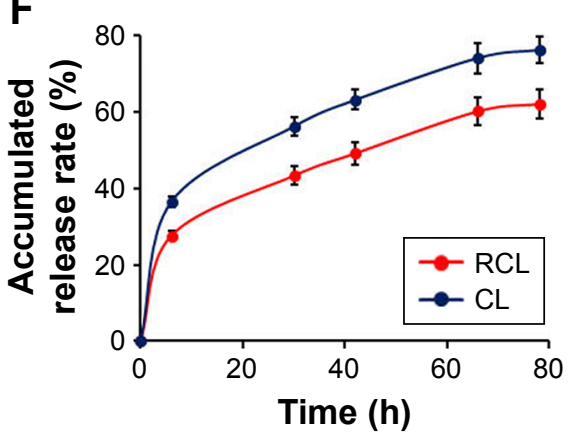

Figure 2 Characteristics of the nanoliposomes. (A) Aqueous solution of the nanoliposomes (a) appeared yellow under visible light, and (b) exhibited green fluorescence under ultraviolet light. (B) The fluorescence absorbance of the liposomes. (C) Dynamic light scattering measurement. The shape of the nanoliposomes was observed by (D) TEM and (E) AFM. (F) In vitro curcumin release from $\mathrm{CL}$ and $\mathrm{RCL}$ in $\mathrm{PBS}(\mathrm{pH} 7.4)$ with $2 \% \mathrm{SDS}$ at $37^{\circ} \mathrm{C}$. Data are represented as mean $\pm \mathrm{SD}$ ( $\mathrm{n}=3$ ).

Abbreviations: TEM, transmission electron microscopy; AFM, atomic force microscopy; CL, curcumin liposome; RCL, RDP-modified curcumin nanoliposomes.

under TEM and AFM (Figure 2D and E). The entrapment efficiencies of RCL and CL were $88.6 \%$ and $85.4 \%$, respectively. Furthermore, the result of in vitro release of curcumin showed that about $80 \%$ of curcumin in CL was released after $\mathrm{CL}$ were suspended in release medium for $78 \mathrm{~h}$ with a halftime $\left(t_{1 / 2}\right)$ of about $20 \mathrm{~h}$. However, RCL exhibited a relatively slower release rate that only about $60 \%$ of curcumin was released with a $t_{1 / 2}$ of about $44 \mathrm{~h}$, indicating that RCL had higher stability than CL (Figure 2F).

\section{Cell uptake and specific inhibition of U25 IMG cell growth by RCL}

To evaluate the cell selectivity of RCL, neuronal cells (U251MG cells) and nonneuronal cells (HeLa cells) were used in the study. The cell selectivity of RCL was identified using the confocal microscope observation and cell inhibition measurement. The images of microscopic observation showed that strong green fluorescence was observed within U251MG cells after incubation with RCL for $2 \mathrm{~h}$, and the fluorescence located in the whole cells (Figure 3A and B), which conforms to a diverse range of intracellular molecular targets of curcumin, including nucleus and cytoplasm. ${ }^{31} \mathrm{How}-$ ever, a relatively weak fluorescence was shown by HeLa cells after RCL addition in the media for $2 \mathrm{~h}$ (Figure $3 \mathrm{~A}$ and $\mathrm{B}$ ).
The results suggested that RCL would selectively enter neuronal cells. Also, the images of RCL-treated U251MG cells exhibited apoptotic features, such as cell shrinkage and formation of apoptotic bodies (Figure 3A), which implied that RCL might inhibit U251MG cell growth partly though induction of cell apoptosis.

When U251MG cells were respectively treated with different concentrations of liposomes for $48 \mathrm{~h}$, the cell growth was inhibited in a dose-dependent manner. However, RCL exhibited stronger inhibition effect than CL at the dose of $4 \mu \mathrm{M}$ (Figure 3C). Furthermore, medium inhibition concentrations $\left(\mathrm{IC}_{50}\right)$ of the liposomes were measured, and the results showed that RCL had higher growth inhibition efficiency in U251MG cells than CL $(18.1 \pm 2.9$ vs $60.1 \pm 3.7 \mu \mathrm{M})$ (Figure 3D). These results indicated that RCL had obvious cell selectivity and inhibition activity on U251MG cells.

\section{Mechanism of internalization of RCL into U25IMG cells}

Since peptide derivatives of RVG, including RVG29 and RDP, are suggested to specifically enter cells through nAch receptor- or GABA receptor-mediated, energy-dependent endocytosis mechanism, ${ }^{32,33}$ we investigated whether RCL was internalized into nerve cells through the similar pathway 

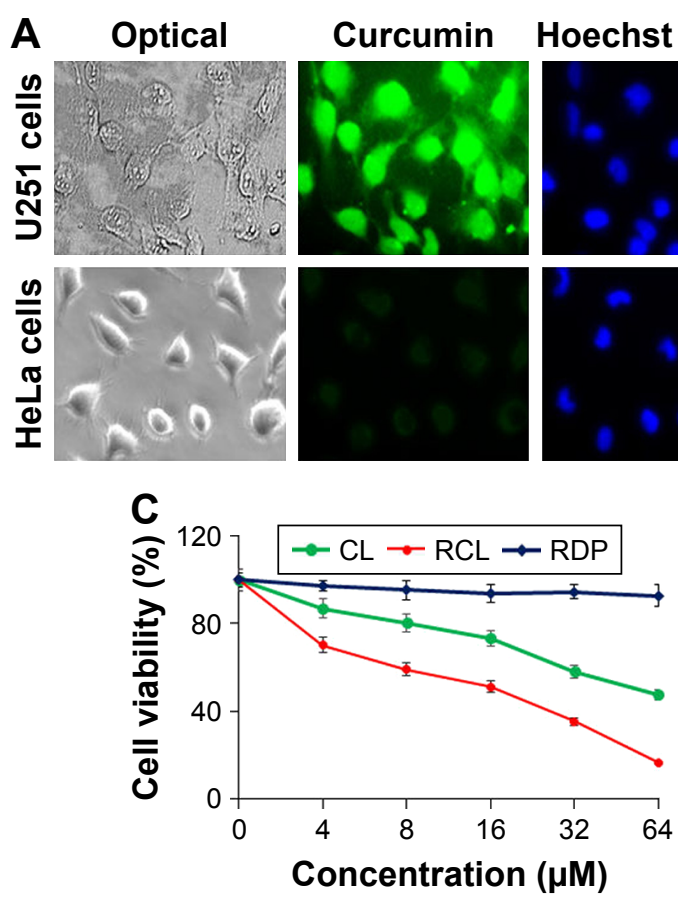

B

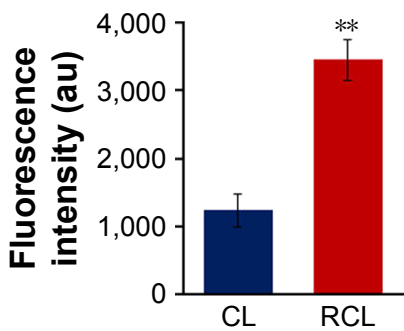

D

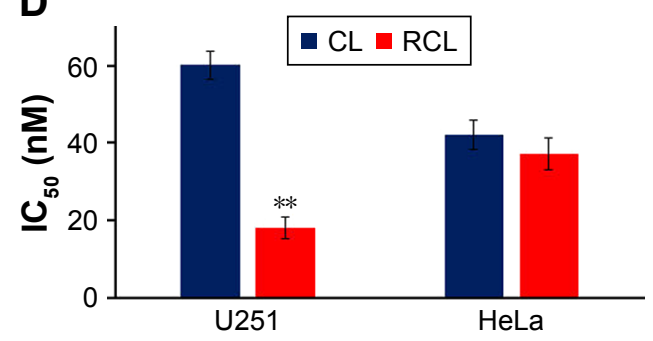

Figure 3 RCL specifically entered U25IMG cells to inhibit the cell growth. (A) Fluorescence images of U25IMG and HeLa cells treated with RCL for 6 h. (B) Fluorescence intensity of U25IMG and HeLa cells treated with $R C L$. ${ }^{* *} p<0.01$ refers to a significant difference as compared to the $C L$ group. (C) Cell viability was measured after the U25IMG cells were respectively treated with the liposomes and RDP. (D) IC 50 was calculated and compared between CL and RCL to determine the selective inhibitory activity of $\mathrm{RCL}$ on glioma cells. **p $<0.0$ I refers to a significant difference as compared to the $\mathrm{CL}$ group.

Abbreviations: CL, curcumin liposome; RCL, RDP-modified curcumin nanoliposomes; U25I, U25IMG cells.

as the targeting peptides. The impact of temperature on RCL transport efficiency was firstly evaluated, for which U251MG cells were incubated with RCL at $37^{\circ} \mathrm{C}$ or $4^{\circ} \mathrm{C}$ for $30 \mathrm{~min}$, and the transport efficiency was measured using a fluorescence detector. The results showed that the fluorescence intensity in RCL-treated cells increased in a concentration-dependent manner at $37^{\circ} \mathrm{C}$, but a relatively low fluorescence intensity appeared at $4^{\circ} \mathrm{C}$ (Figure $4 \mathrm{~A}$ ), suggesting that RCL could efficiently enter metabolically active cells.

Moreover, endocytic inhibitors and neurotransmitters were used respectively to explore the internalization mechanism of the RCL. The results showed that RCL internalization was significantly prevented by $\mathrm{NaN}_{3}$ (energy-depleting agent), colchicine (microtubule-disrupting reagent), and cyto-D (actin microfilament inhibitor), confirming that cell internalization of the RCL was an energy-dependent, microtubule- and microfilament-involved endocytosis process (Figure 4B). In addition, cell uptake of the RCL was significantly inhibited by the cholinergic neuron neurotransmitter Ach, which suggested that Ach receptor-mediated endocytosis pathway could be involved in the liposome internalization. Meanwhile, there was no
A

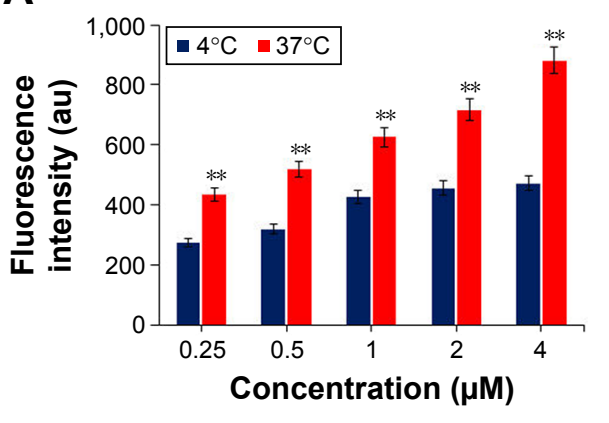

B

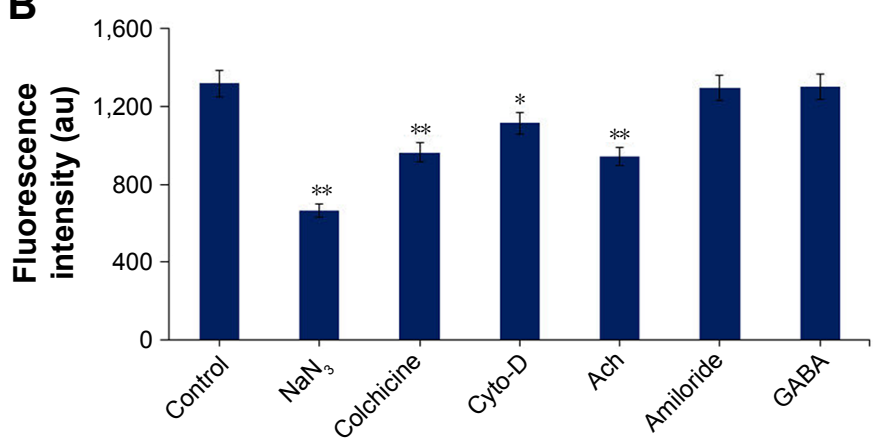

Figure 4 Mechanism of internalization of RCL into U25IMG cells. (A) Cellular uptake of RCL (concentrations, $0-4 \mu \mathrm{M}$ ) at $37^{\circ} \mathrm{C}$ or $4^{\circ} \mathrm{C}$. (B) Endocytosis mechanism involved in the cell internalization of RCL. The cells were pretreated with endocytosis inhibitors or neurotransmitters, and then the RCL was added into the cells. Data are represented as mean \pm SD $(n=3)$. $* p<0.05$ and $*_{p} p<0.01$ compared with the control.

Abbreviations: cyto-D, cytochalasin D; Ach, acetylcholine; GABA, $\gamma$-aminobutyric acid; RCL, RDP-modified curcumin nanoliposomes. 
significant difference among controls and the cells treated with amiloride and GABA (Figure 4B), indicating that the RCL entered the U251MG cells without macropinocytosis and GABA receptor-mediated endocytosis pathways. These results showed that the internalization mechanism of RCL would be associated with Ach receptor-mediated, energydependent endocytosis.

\section{Inhibition mechanism of RCL in U25 IMG cells}

Curcumin inhibits the growth of various tumor cells through diverse mechanisms. For example, one study suggests that curcumin induces apoptosis in the G2 phase of cell cycle in mammary epithelial carcinoma cells, ${ }^{20}$ and another study demonstrates that curcumin leads to the accumulation of cells in G1 phase in tumor cells. ${ }^{34}$ However, the cell cycle effect of curcumin on U251MG cells remains unclear.

Here, we investigated the effects of RCL on cell cycle and apoptosis using flow cytometry. The results exhibited that the percentage of $\mathrm{S}$ phase of cell cycle significantly increased from $28.15 \%$ to $52.82 \%$ after the cells received RCL treatment, compared to $39.49 \%$ of the cells treated with CL (Figure 5A), suggesting that RCL induced the accumulation of cells in G1 phase of the cell cycle in U251MG cells. Moreover, the results of cell apoptosis showed that the cells treated with RCL had higher apoptotic rate $(33.45 \%)$ that that of CL (11.30\%) (Figure 5B). These results suggested that the RCL could cause cell cycle arrest at the $\mathrm{S}$ phase of the cell cycle and induced cell apoptosis. ${ }^{35,36}$

\section{In vivo imaging}

To identify the brain-targeting effect of RCL, mice were intravenously injected with RCL respectively, and fluorescence was observed using the in vivo imaging system. The results showed that the fluorescence appeared in the brains of the mice treated with RCL (Figure 6A and B), while there was little fluorescence in the brains of CL-treated mice, indicating that RCL could cross the BBB and enter the brains.

The results of the in vivo pharmacokinetics of the nanoliposomes showed that $t_{1 / 2}$ of the RCL in plasma was $5.26 \mathrm{~h}$, which was slightly shorter than that of CL (6.05 h) (Figure 6C). However, the fluorescence of RCL-treated mice was significantly stronger than that of the mice treated with CL, indicating that the RCL entered the brain (Figure 6D). Moreover, the brain sections of RCL-treated mice showed that obvious fluorescence appeared in the neural cells (cytoplasm and nucleus), while weak fluorescence appeared in the neural cells of CL-treated mice (Figure 6E).

Furthermore, we examined the targeting effect of RCL in glioma-bearing mice. Intracranial glioma mice model was
A

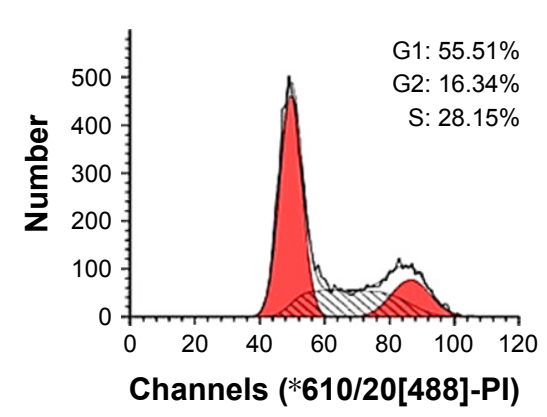

B

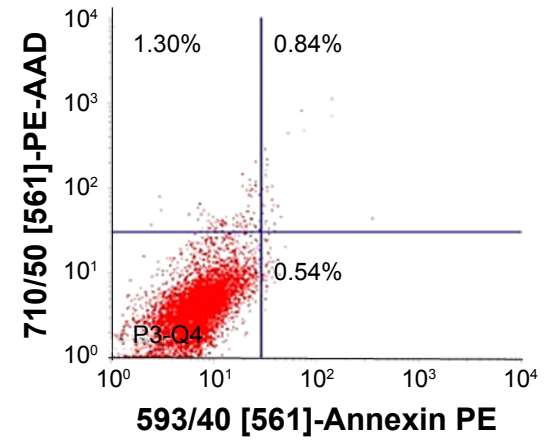

CL

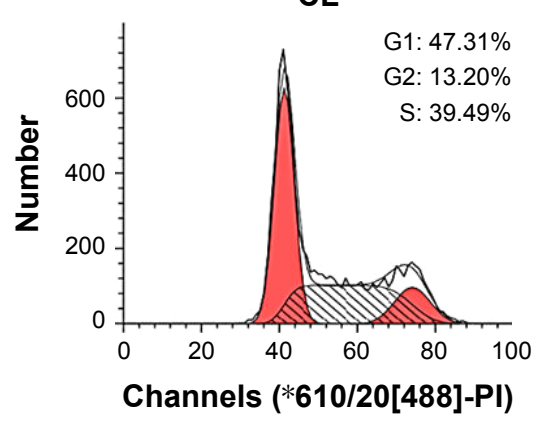

CL

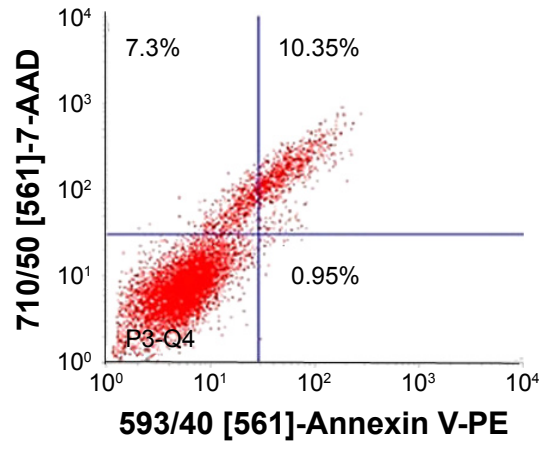

RCL

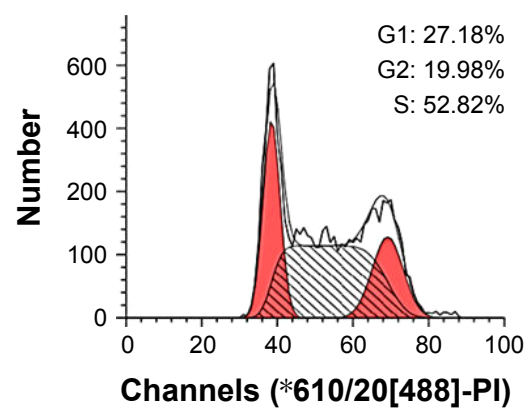

RCL

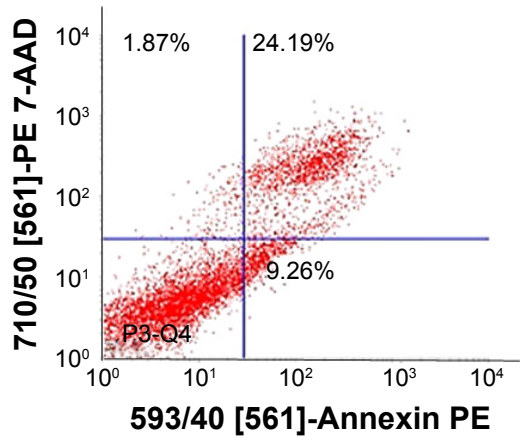

Figure 5 The mechanism of RCL inhibition of U25IMG cells growth. (A) Cell cycle distribution and (B) apoptosis of U25IMG cells after CL and RCL treatment. RCL promotes apoptosis more than $\mathrm{CL}$.

Abbreviations: CL, curcumin liposome; RCL, RDP-modified curcumin nanoliposomes. 
A

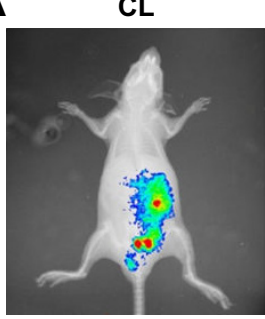

C

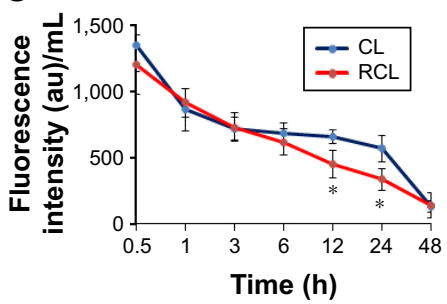

RCL

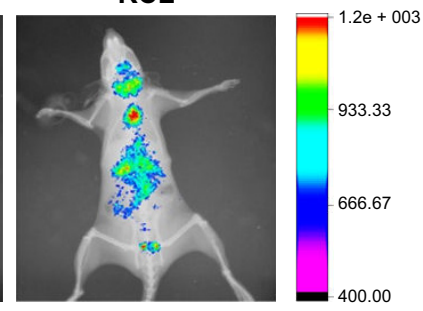

B Brain Kidney Heart Lung Liver

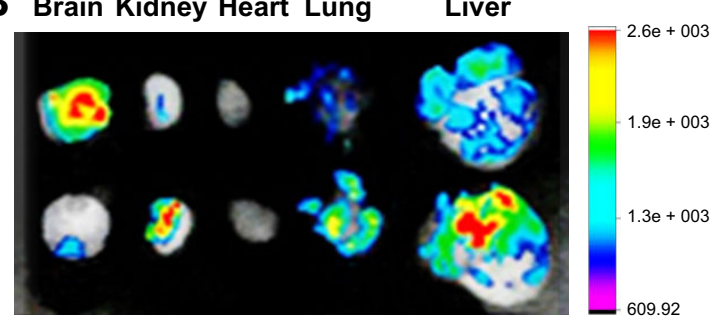

$\mathbf{E}$

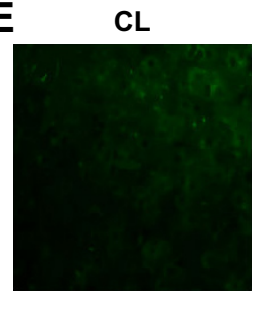

RCL

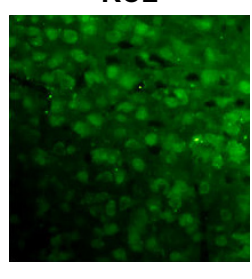

Figure 6 In vivo distribution of the RCL. Images were taken at $2 \mathrm{~h}$ after intravenous injection of the nanoliposomes. (A) In vivo imaging. (B) Tissue imaging. (C) Plasma pharmacokinetics after the mice received $\mathrm{CL}$ and RCL. (D) Fluorescence intensity of curcumin in the brain at different time points (0.5, I, 3, 6, I2, and $24 \mathrm{~h}$ ). Data are represented as mean $\pm S D$ ( $n=4$ for each time point). ${ }^{*} p<0.05$ and ${ }^{* *} p<0.01$ compared with the $C L$ group. (E) Brain sections after the mice were injected with $C L$ and $\mathrm{RCL}$ for $2 \mathrm{~h}$.

Abbreviations: $\mathrm{CL}$, curcumin liposome; RCL, RDP-modified curcumin nanoliposomes.

prepared through intra-striatal injection of U251MG cells to form xenograft tumor. The brain slices of glioma model mice showed visible tumor mass in the right striatum with high cell density and clear boundary compared to normal brain tissue after 2 weeks of cell transplantation (Figure 7A), confirming that the intracranial glioma mice model was prepared successfully.

After 2 weeks of cell transplantation, the liposomes were intravenously injected into the mice. The results of in vivo imaging showed that obvious fluorescence was detected in the mice brain after the mice received RCL injection $(20 \mathrm{mg} / \mathrm{kg}$ of body weight), and the fluorescence concentrated in glioma area (Figure 7B). However, the mice treated with the same dose of CL showed relatively weak fluorescence in glioma (Figure 7B). The results suggested that RCL could efficiently enter the brain and then the tumor region.

\section{RCL prolonged the survival time of glioma-bearing mice}

After about 10 days of U251MG cell transplantation, the mice appeared obviously fragile, and showed faltering growth and decrease of foraging behaviors. At 15-26 days after transplantation, they appeared motionless and to be in coma and had to be euthanized. Glioma formation rate in the study reached $80 \%$, and the mean survival time of the glioma-bearing mice was around 23 days.

For RCL therapy, the mice received the liposomes at day 7 following cell transplantation. The images of HE staining of glioma tissue showed classic characteristic features of xenograft tumor at 14 days after tumor cell transplantation, such as dense cell mass, nuclear atypia, mitoses, and necrosis (Figure 7C). However, cell mass and tumor volume were significantly decreased in the RCL-treated mice (Figure 7C and D), indicating that RCL inhibited glioma cell growth in vivo.

The results also showed that the mice treated with CL had prolonged survival time from 23 to about 26 days, while the mice that received RCL treatment could survive about 33 days and their symptoms relatively improved compared with the corresponding control mice (Figure 7E). In addition, the mean survival time of RCL-treated mice was 22 days (Figure 7F), which was longer than that of glioma model mice (14 days) and CL-treated mice (17 days). These results showed that RCL had significant therapeutic effect on glioma.

\section{Conclusion}

Glioma is the most prevalent and the most aggressive of primary brain tumors. Here, we showed for the first time that curcumin-loaded RCL inhibited human glioma cell proliferation and tumor growth using the intracranial glioma mice model. The RCL could arrive in the brain and glioma region, and then were internalized into the glioma cells perhaps through Ach receptor-mediated endocytosis pathway. The glioma cell inhibition mechanism of RCL was partly due to cell cycle arrest at the $\mathrm{S}$ phase and induction of cell apoptosis. This study would provide a potential strategy for treatment of human malignant gliomas. 
A

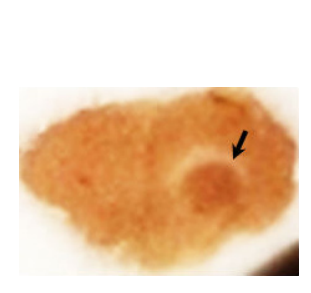

B

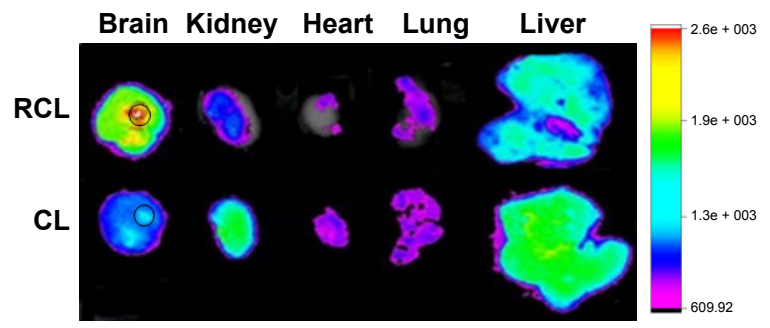

D

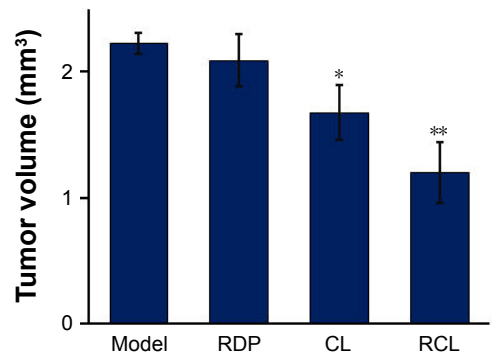

C

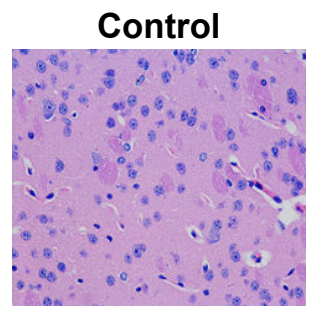

Glioma model

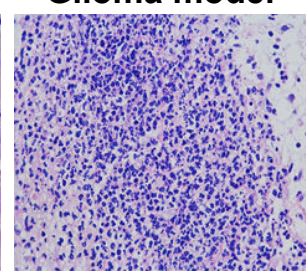

RDP

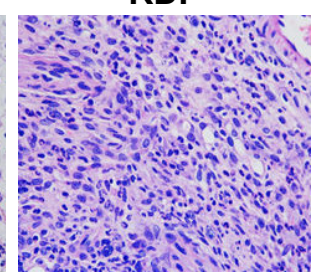

CL

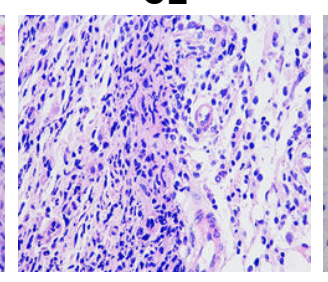

$\mathrm{RCL}$

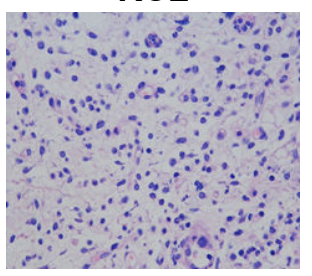

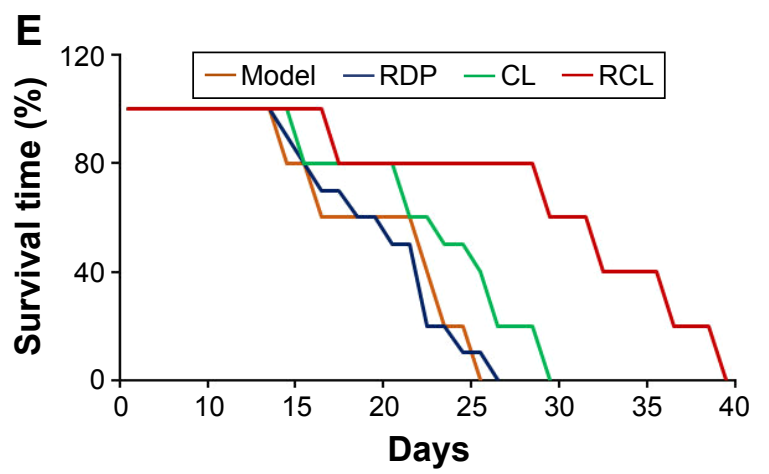

F

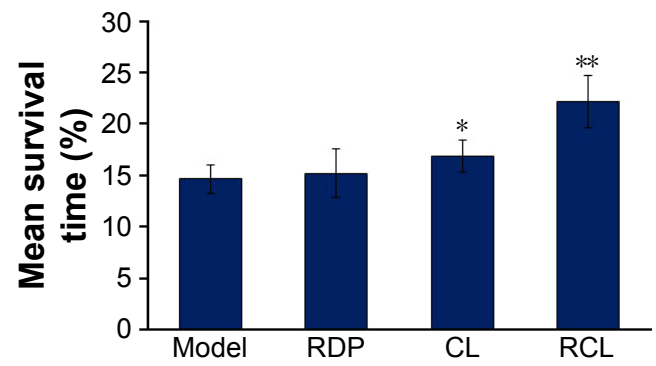

Figure 7 Effect of RCL on intracranial glioma model mice. (A) Brain slices of glioma model mice. Black arrow points to glioma tissues. (B) Tissue imaging of glioma-bearing mice treated with $20 \mathrm{mg} / \mathrm{kg} \mathrm{CL}$ and RCL, respectively. (C) Representative images of HE staining of mice brain sections ( $\times 400)$. (D) Tumor volume. Data are represented as mean $\pm S D\left(n=4-6\right.$ for each group). ${ }^{*} p<0.05$ and $* * p<0.01$ compared with the glioma of model mice. (E) Survival curve and $(\mathbf{F})$ mean survival time of the glioma-bearing mice treated with the liposomes $(n=8-10$ for each group). $* p<0.05$ and $* * 0<0.01$ compared with the model mice.

Abbreviations: $\mathrm{CL}$, curcumin liposome; RCL, RDP-modified curcumin nanoliposomes; RDP, RVG-derived peptide; HE, hematoxylin-eosin staining.

\section{Acknowledgment}

This work was supported by a grant from the National Natural Science Foundation of China (81273416).

\section{Disclosure}

The authors report no conflicts of interest in this work.

\section{References}

1. Ohgaki H, Kleihues P. Population-based studies on incidence, survival rates, and genetic alterations in astrocytic and oligodendroglial gliomas. J Neuropathol Exp Neurol. 2005;64(6):479-489.

2. Carlberg M, Hardell L. Evaluation of mobile phone and cordless phone use and glioma risk using the Bradford Hill viewpoints from 1965 on association or causation. Biomed Res Int. 2017;2017:9218486.

3. Daher A, de Groot J. Rapid identification and validation of novel targeted approaches for Glioblastoma: a combined ex vivo-in vivo pharmaco-omic model. Exp Neurol. 2018;299(Pt B):281-288.

4. Chen R, Cohen AL, Colman H. Targeted therapeutics in patients with high-grade gliomas: past, present, and future. Curr Treat Options Oncol. 2016;17(8):42.
5. Mangiola A, Anile C, Pompucci A, Capone G, Rigante L, De Bonis P. Glioblastoma therapy: going beyond Hercules columns. Expert Rev Neurother. 2012;10(4):507-514.

6. Wadajkar AS, Dancy JG, Hersh DS, et al. Tumor-targeted nanotherapeutics: overcoming treatment barriers for glioblastoma. Wiley Interdiscip Rev Nanomed Nanobiotechnol. 2017;9(4):e1439.

7. Miranda A, Blanco-Prieto MJ, Sousa J, Pais A, Vitorino C. Breaching barriers in glioblastoma. Part II: Targeted drug delivery and lipid nanoparticles. Int J Pharm. 2017;531(1):389-410.

8. Touat M, Idbaih A, Sanson M, Ligon KL. Glioblastoma targeted therapy: updated approaches from recent biological insights. Ann Oncol. 2017;28(7):1457-1472.

9. Pardridge WM. Drug transport across the blood-brain barrier. J Cereb Blood Flow Metab. 2012;32(11):1959-1972.

10. Gramlich PA, Westbroek W, Feldman RA, et al. A peptide-linked recombinant glucocerebrosidase for targeted neuronal delivery: design, production, and assessment. J Biotechnol. 2016;221:1-12.

11. Fu A, Wang Y, Zhan L, Zhou R. Targeted delivery of proteins into the central nervous system mediated by rabies virus glycoprotein-derived peptide. Pharm Res. 2012;29(6):1562-1569.

12. Zhang E, Fu A. A new strategy for specific imaging of neural cells based on peptide-conjugated gold nanoclusters. Int J Nanomedicine. 2015; 10:2115-2124. 
13. Huey R, O'Hagan B, McCarron P, Hawthorne S. Targeted drug delivery system to neural cells utilizes the nicotinic acetylcholine receptor. Int J Pharm. 2017;525(1):12-20.

14. Ovadje P, Roma A, Steckle M, Nicoletti L, Arnason JT, Pandey S. Advances in the research and development of natural health products as main stream cancer therapeutics. Evid Based Complement Alternat Med. 2015;2015:751348.

15. Wu WS, Chien CC, Liu KH, Chen YC, Chiu WT. Evodiamine prevents glioma growth, induces glioblastoma cell apoptosis and cell cycle arrest through JNK activation. Am J Chin Med. 2017;45:879-899.

16. Wang X, Deng J, Yuan J, et al. Curcumin exerts its tumor suppressive function via inhibition of NEDD4 oncoprotein in glioma cancer cells. Int J Oncol. 2017;51(2):467-477.

17. Goo S, Choi YJ, Lee Y, Lee S, Chung HW. Selective effect of curcumin on $\mathrm{CdSe} / \mathrm{ZnS}$ quantum-dot-induced phototoxicity using UVA irradiation in normal human lymphocytes and leukemia cells. Toxicol Res. 2013;29(1):35-42.

18. Syng-Ai C, Kumari AL, Khar A. Effect of curcumin on normal and tumor cells: role of glutathione and bcl-2. Mol Cancer Ther. 2004;3(9): 1101-1108

19. Kumar RR, Malhotra A. Curcumin as a protector for normal cells during bortezomib therapy. Hum Exp Toxicol. 2015;34(7):780-783.

20. Choudhuri T, Pal S, Das T, Sa G. Curcumin selectively induces apoptosis in deregulated cyclin D1-expressed cells at G2 phase of cell cycle in a p53-dependent manner. J Biol Chem. 2005;280(20):20059-20068.

21. Sirohi VK, Popli P, Sankhwar P, et al. Curcumin exhibits anti-tumor effect and attenuates cellular migration via Slit-2 mediated downregulation of SDF-1 and CXCR4 in endometrial adenocarcinoma cells. J Nutr Biochem. 2017;44:60-70.

22. Mansouri Z, Sabetkasaei M, Moradi F, Masoudnia F, Ataie A. Curcumin has neuroprotection effect on homocysteine rat model of Parkinson. J Mol Neurosci. 2012;47(2):234-242.

23. Huang HC, Xu K, Jiang ZF. Curcumin-mediated neuroprotection against amyloid- $\beta$-induced mitochondrial dysfunction involves the inhibition of GSK-3ß. J Alzheimers Dis. 2012;32(4):981-996.

24. Oswald M, Geissler S, Goepferich A. Determination of the activity of maleimide-functionalized phospholipids during preparation of liposomes. Int J Pharm. 2016;514(1):93-102.
25. Hermanson GT. The Reactions of Bioconjugation. Boston: Academic Press; 2013.

26. Dutta D, Donaldson JG. Search for inhibitors of endocytosis: intend specificity and unintended consequence. Cell Loqist. 2012;2(4): 203-208.

27. Grassman R, Brastianos H, Blakeley JO, et al. Combination of antiVEGF therapy and temozolomide in two experimental human glioma models. J Neurooncol. 2014;116(1):59-65.

28. Liu X, Lu D, Ma P, et al. Hugl-1 inhibits glioma cell growth in intracranial model. J Neurooncol. 2015;125(1):113-121.

29. Hinna AH, Hupfeld S, Kuntsche J, Bauer-Brandl A, Brandl M. Mechanism and kinetics of the loss of poorly soluble drugs from liposomal carriers studied by a novel flow field-flow fractionation-based drug release-/transfer-assay. J Control Release. 2016;232:228-237.

30. Xue J, Zhao Z, Zhang L, et al. Neutrophil-mediated anticancer drug delivery for suppression of postoperative malignant glioma recurrence. Nat Nanotechnol. 2017;12(7):692-700.

31. Kuwar A, Barik A, Mishra B, Rathinasamy K, Pandey R, Priyadarsini KI. Quantitative cellular uptake, localization and cytotoxicity of curcumin in normal and tumor cells. Biochim Biophys Acta. 2008;1780(4): 673-679.

32. Huey R, Hawthorne S, McCarron P. The potential use of rabies virus glycoprotein-derived peptides to facilitate drug delivery into the central nervous system: a mini review. J Drug Target. 2017;25(5):379-385.

33. Fu A, Zhao Z, Gao F, Zhang M. Cellular uptake mechanism and therapeutic utility of a novel peptide in targeted-delivery of proteins into neuronal cells. Pharm Res. 2013;30(8):2108-2117.

34. Aggarwal BB, Banerjee S, Bharadwaj U, Sung B, Shishodia S, Sethi G. Curcumin induces the degradation of cyclin E expression through ubiquitin-dependent pathway and up-regulates cyclin-dependent kinase inhibitors p21 and p27 in multiple human tumor cell lines. Biochem Pharmacol. 2007;73(7):1024-1032.

35. Oyagbemi AA, Saba AB, Ibraheem AO. Curcumin: from food spice to cancer prevention. Asian Pac J Cancer Prev. 2009;10(6):963-967.

36. Reuter S, Eifes S, Dicato M, Aggarwal BB, Diederich M. Modulation of anti-apoptotic and survival pathways by curcumin as a strategy to induce apoptosis in cancer cells. Biochem Pharmacol. 2008;76(11): $1340-1351$.
International Journal of Nanomedicine

\section{Publish your work in this journal}

The International Journal of Nanomedicine is an international, peerreviewed journal focusing on the application of nanotechnology in diagnostics, therapeutics, and drug delivery systems throughout the biomedical field. This journal is indexed on PubMed Central, MedLine, CAS, SciSearch ${ }^{\circledR}$, Current Contents ${ }^{\circledR} /$ Clinical Medicine,

\section{Dovepress}

Journal Citation Reports/Science Edition, EMBase, Scopus and the Elsevier Bibliographic databases. The manuscript management system is completely online and includes a very quick and fair peer-review system, which is all easy to use. Visit http://www.dovepress.com/ testimonials.php to read real quotes from published authors. 